\title{
An adaptive intelligent alarm system for wireless sensor network
}

\author{
Ayman Dawood Salman ${ }^{1}$, Osamah Ibrahim Khalaf ${ }^{2}$, Ghaida Muttasher Abdulsaheb ${ }^{3}$ \\ ${ }^{1,3}$ University of technology Baghdad-Iraq/Computer engineering Department, Iraq \\ ${ }^{2} \mathrm{Al}-\mathrm{Nahrain}$ University, College of Information Engineering, Iraq
}

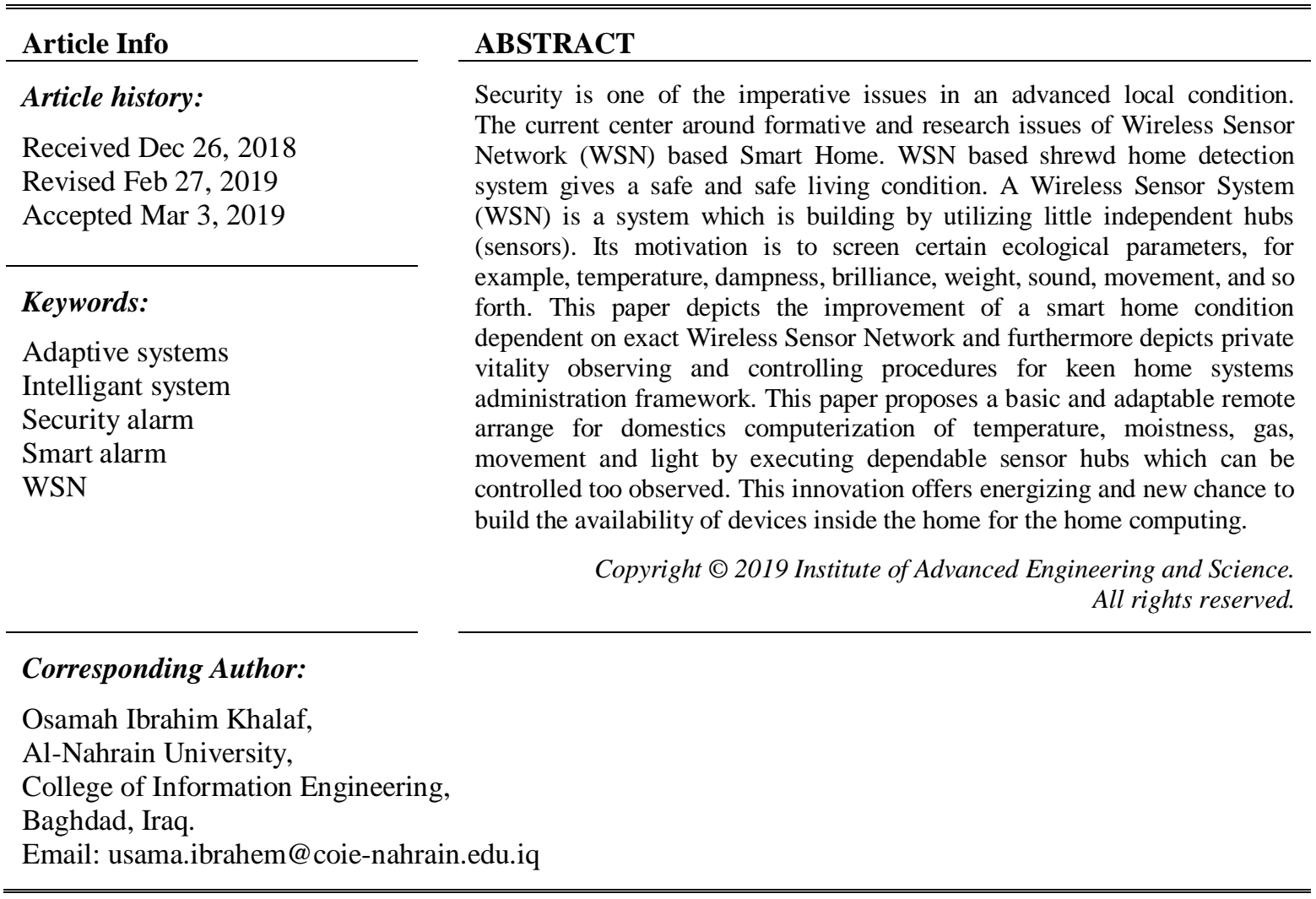

\section{INTRODUCTION}

Security alarm comprises a portion of the serious issues confronting our quick world at the current days. Individuals live with dread of becoming assaulted by robbers, criminals, etc. Regardless of whole exertion, assets and periods that have been given for the improvement of devices which will in turn lessen wrongdoing values and create the world which is more secure location for living, these issues are stay on the expansion. And they offered for ascending of the requirement for an expanding advancement in innovation of alert frameworks that uses different standards, for example, infrared movement identification, light (photograph) delicate electronic device, etc. Indeed, even with the presentation of these alert frameworks which have diminished enormously the dimension of instability, there is as yet an issue of false caution which should be limited [1]. So as to adequately lessen the dimension of weakness and evade false alerts which can make pointless turmoil, a touch actuated security framework is required. This framework on the off chance that legitimately structured will give security and guarantee alerts are initiated just when an unapproved individual endeavor to access the ensured territory or device by contacting the passage or then again some other piece of the device. an Alarm (caution) is a boisterous commotion or flag for alarming or advising individuals of peril or an issue. the alert framework is subsequently a security framework that creates a type of sound to caution individuals of a specific threat. The advancement of alert frameworks began with a production of person. People needed getting ready data and received the type of flagging, outcry and yelling. This was later supplanted by applauding of gongs by city proclaimers for cautioning the network so as to disperse data in the 
previous African customs. Every one of these techniques of raising alarm was re unrefined, inconsistent and wasteful. With the enhancement in science, these grungy methodologies for making alert were displaced using electrical alert systems in the previous year [2]. The mentioned system structures make alert with no people effort. When it distinguishes the particular banner, it sends a notification in sort of raucous voice or confusion depending upon its arrangement [3-4]. Be that as it may, organizations subject to security advantage gear course of action have been composing unmistakable plans to repulse cheats and vandals from open domains not work for them [5]. Recently, a new period of electrical alert framework which happened in different measurements of progression [6]. With the continuous addition in bad behavior rates, it has end up crucial to verify our structures and properties with tasteful prosperity contraptions with an extended element of innovation [5]. The cost of these security contraptions depend upon the equipment development and the application need. These security contraptions are known as the progressed electronic alert system [7]. By virtue of the development recognizable proof, the ultrasonic method is ordinarily utilized, while pointing identifier cheat ready assistants in disclosure of unapproved individual at a specific zone [8].

\section{RELATED WORK}

Using detecting gadgets for accommodation, wellbeing, security and nature of administration reason for existing isn't new, however the application, cost, structure technique and unwavering quality of the framework changes. In studies of [9-11], the creators deem the utilization of infra-red beams to include a quantity of travelers the vehicle and furthermore smart home machines by means of short message administrations with the end goal of security and people accommodation. In $[5,8,9]$, a criminal alert system was organized. The hoodlum alert is delivered utilizing an all-out electrical system hover where by a circle is near with a ring at the yield or a caution so as to give a notice to the person in order to be secured. A central control box screens a couple of development markers and edge screens and sounds an alert when any of them are initiated. Some criminal alerts tackle the possibility of appealing contacts and others on affectability. These days, shut circuit TVs are fused to criminal alerts to identify the nearness of unapproved people. The yield of which is typically an alarm or uproarious speaker alerts to phone programmed devices and other types of frameworks. This provides the capacity of alarming the close persons of conceivable interruption and furthermore fills in as flag for the responsible persons"[12]. Auto calling appended to thief alerts have customized to call the responsible persons and send the recorded message which educates the persons in $\mathrm{f}$ the house for being burgled. In study of [13-14], a novel coercion caution had used, it is commonly electrical gadgets which fluctuate generally for capacities. They are utilized in case of risk to send alert signs to explicit area, and are ordinarily sorted as coercion caution frameworks. The sorts of coercion caution frameworks are: Identification alert: In this framework, a straightforward compact gadget is utilized to recognize the get to capable work force (proprietor) of the gadget, Panic catch alert [15-16]. A push catch mounted in a settled area, and an area caution: a versatile gadget that finds and tracks the individual who actuated caution [17]. The frenzy catch is the most widely recognized sort of pressure alert. It is found in schools, banks, workplaces and so on [18-19]. The gadgets and programming of such a framework delivers a situating image on a comfort board or guide like showcase. Also, the vast majority of the papers referenced above does not think about cost, dependability and sturdiness in their structure technique, or more all, this paper utilizes straightforward and simple to get segments to accomplish its ideal objectives.

\section{PROPOSED SYSTEM}

In this section, the framework configuration is actualized in three units as appeared which are: power supply, trigger unit, and alert unit.

\subsection{Power Supply Part}

It is a two ways programmed power framework. It fetches contribution from the two prime resources the first one is the prime supply and battery supply [20]. It is autonomous supply frameworks have associated with the hand-off commutator that goes about as a programmed relay which change to on state any of the accessible info supply to the fundamental circuit. It considers as a unit that gives control to a next 2 parts of the system. The schematic chart of this part comprises of two supply input sources. E1 is a defensive wire used to avoid abundance current from the whole system." TT1 is a stage down transformer. DD1, DD2, DD3, and DD4 aare rectifier adiodes. CC1 is a channel capacitor. I1 is a controller I. Relay is a hand-off switch. RR2 are acurrent restricting resistors ensuring LED1 and LED2 separately. LED11 has utilized to demonstrate the nearness of amains supply awhile LED12 is utilized to show that current is going inside the trigger part. DD5 and DD6 are defensive diodes." 


\subsection{The Trigger Part}

The schematic graph of the trigger unit comprise of three noteworthy segments which are clock (CCC2), Transistor (TF1) and a transfer (Relay2). The clock (CCC2) provides a trigger current that turns out by using its stick three at whatever point stick two is impelled using a sensor. Pins number (4 and 8 ) are related with power part while stick 1 is connected to the ground. (RR3) \& (CC2) chooses the time out and time of the 555 clock. Moreover, (RR4) chooses an affectability for the sensor. The signal of pin3 (current of the trigger) is heightened by (TTT1). R5 go about as base resisance to TTT1 that is working in like way maker mode. A current from (TF1) makesthe exchange (Relay2) for working in like manner trading on the alert/intensifier unit to control provider for a term of periode chose when out time of the 555 clock (CCC2). DD7 goes about as a substitution diode verifying the (TTT1) from Back-EMF made by the hand-off circles. The check in this unit works in a monostable mode.

\subsection{Alarm Unit}

This unit comprises of three essential parts which are; Two 555 clocks CCC 3 and CCC4 working in steady style for creating a sire notification and (TTT2) utilized for more enhancement in sound yield. CCC3 works at a great recurrence of $240 \mathrm{~Hz}$, then go about as a avoltage oscillatorawhile delivering aasquare-wave. $\mathrm{CCC} 4$ results in a square wave much less recurrence of $0.25 \mathrm{~Hz}$ this lower recurrence adjusts the mode of the unfaltering tone from $\mathrm{CCC} 3$ to the ideal alarm notification. The signal of IC4 is really connected using RR9 to manage the voltage of CCC 3 . The low recurrence $(0.25 \mathrm{~Hz})$ yield from $\mathrm{CCC} 4$ is utilized to regulate the high recurrence $(240 \mathrm{~Hz})$ delivered by IC 3 along these lines substituting the recurrence of activity of CCC 3 to create an alarm sound rather than a nonstop $240 \mathrm{~Hz}$ tone. The last alarm note is accessible at apin 3 of IC 3 however its highest current is $0.0213 \mathrm{~A}$. This current isn't adequate for $4 \mathrm{w}, 9 \mathrm{ohms}$ speaker. The pin 3 yield of CCC 3 is in this way nourished to the transistor TTT2 for further enhancement empowering it to control the speaker in this manner creating an uproarious capable of being heard alarm sound.

\section{PROPOSED SYSTEM DESIGN AND IMPLEMENTATION}

$A(220 / 20 \mathrm{v})$ is the transformer that was picked in light of the fact that its rating is equipped for satisfying the present need of the system and it is ensured by A1 intertwine versus abundance current. A constraining resistance (RR1) for the LED1 was determined as:

RR1 = dropped V/ Current led

so that

RR1 $=($ supply voltage - Led Voltage $) /$ Current led

Where supply voltage is equal to $20 \mathrm{v}$, led voltage $=1.9$ and Current of led $25 \mathrm{~mA}$

$20 .-1.9 / 0.025=724 \Omega$

So the identical value for the resistor 1 which can be used in the design must be closest to this value LED current $=20 / 724=0.027 \mathrm{~mA}$

PIV possible in an auxiliary end to end transformer is double the end to end voltage [21-23].

So that PIV $=2 \times 20=36 \mathrm{~V}$.

This was done to keep away from harm to the diodes on the off chance that switch activity happens. The estimation of the channel [24].

capacitor CC was gotten as:

$\mathrm{CC}=1 / 4 c c=2 \sqrt{3 \text { frequency } * \text { ripple factor }}$

Given that :

Frequency $=50 \mathrm{~Hz}$

$\mathrm{y}=$ ripple factor $=0.051$

so that

$\mathrm{CC}=1 / 512=1.9 \mu \mathrm{F}$

Regarding RR2

When the supply voltage is equal to 14 and the led of the $1.9 \mathrm{~A}$

So that

Indonesian J Elec Eng \& Comp Sci, Vol. 15, No. 1, July 2019 : 142 - 147 
$\mathrm{RR} 2=(140-1.9) / 0.02=605 \Omega$

So the identical value for the resistor 2 which can be used in the design must be closest to this value.

In trigger part side the period time is referred to as $(\mathrm{P})$, frequency is referred to as (FR) were calculated by the rates of RR4 and CC2 as follows:

$P=1.2(R R \times C C)$

But RR3 $=110 \mathrm{~K} \Omega=110 \times 10^{3} \Omega, \mathrm{CC} 2=40 \times 10^{-6}$

$\mathrm{P}=1.2 *\left(110 \times 10^{3} * 40 * 10^{-6}\right) \mathrm{sec}$

$=5.6$ nearly equal to $5 \mathrm{sec}$

$F R=1 / 5.374=0.178 \mathrm{~Hz}$

The values of RR4 and CC2 were selected in order to give a value that is approximately close to the practical value [25].

\section{RESULTS}

In this study there is a several stages which are followed in order to check the validation and verify the results through the real by using various experiments and calculations. The 1st part of the design which includes supplement of the power had checked and verified, after that the sender and sink and other system design parts had verified. The design was checked by applying different experiments. every part had checked by utilizing " multi- meter " in order to insure that the system designed correctly, after that the other stages of the system have implemented. Which provide a good environment for to check the errors in early stage with less delay. The design of the prototype circuit ha implemented on a $(20 * 30) \mathrm{cm}$ system board. The next part of the design is the system figuring. The selected size of the board has been chosen depended on the previous studies [26-28].

The fundamental purpose of checking testing each segment previously on the (VERO-BOARD) is to dodge a meticulous exertion which takes to dis-bind different signals at the end of each. From the coherence result that applies on the (VEROBOARD) to calculate the system design, it discovered that the system is in an ideal condition as progression was insured. Reproduction of the system design was also happened as referenced before, with the main aim of contrasting the results got from structure figuring's to thata got froma reproduction $[29,30]$.

The twoa outcomes whena contrasted intently compare and just a slight errora in qualities. In order to guaranteea that every onea of the parts to be utilized is practically working, they were first tried with a computerizeda mult- imeter and fizzled onesa supplanteda before at last binding them on the Vero board. then in order to guarantee that there was no breakage in the circuit way on the Vero board, following welding on Vero board, the circuit way was tried utilizing the Digitala Multii-meter. This was made to likewise guarantee congruity of the system on the Vero board, then the circuit was reenacted. The outcome got from the reenactment intently compares to the ideal outcome, with just some slight varieties. Finally, The timeframe for the alert notification was physically tried. it has accomplished utilizing Digital -Stop- Watch and outcome acquired was observed to be $15.5 \mathrm{sec}$. an esteem acquired from the manual testing intently concurs with that got in a plan determinations for example 5.7 seconds..

\section{CONCLUSIONS}

"It tends to be presumed that the main point of making plan, examination and applying of a straightforward and dependable touch delicate security design was implemented, in order to construct a perfect security framework, that was greatly acknowledged in order to finish of a plan procedure. One factor that represents the reasonableness of the thing was the correct selection of parts utilized. The dependability of the whole alert framework has verified by the incorporation of a customized change over switch into thea power supplya unit with the true objective thata thea A.Ca mains supplya and the batterya area cold abundance. Thusly, this guarantees predictable supply of ability to the rule circuit. The viability of the entire system wasa put intoa thought bya the usage of transistor in the customary gatherer modea to couplea the yield of thea circuita to the speakera. Thea systema was attempted and saw to work to subtleties and desires. Summarilya, a decrepit and strong strategy for checkinga the activitiesa of burglarsa and intrudersa has been adequately made, whicha is the purpose of the investigation. Wea can convincinglya say along these lines, that the upsides of havinga this looter ready structure can'ta be aoveremphasized. Ina future, we will find a technique for improvinga the structure by interfacing the ready system witha the microcomputera to help the feasibility of thea entirea structure or joining a propelled gateway lock. 


\section{REFERENCE}

[1] "False alarm", http://www.alarm.org/false/tips/dealer tip/dealer tip.html

[2] Botía JA., Charitos D., A DIY approach to the Internet of Things: A Smart Alarm Clock. In: 9th International Conference on Intelligent Environments. pp. 214-221, IOS Press, 2013. ", TELKOMNIKA (Telecommunication, Computing, Electronics and Control), Vol.13, No.3, September 2015.

[3] Herry Z. Kotta, Kalvein Rantelobo, Silvester Tena, Gregorius Klau, "Wireless Sensor Network for Landslide Monitoring in Nusa Tenggara Timur", TELKOMNIKA (Telecommunication, Computing, Electronics and Control), Vol.9, No.1, April 2011.

[4] M. Y. Hariyawan, A. Gunawan, E. H. Putra, " Use of Mobile Phones as Intelligent Sensors for Sound Input Analysis and Sleep State Detection. ", TELKOMNIKA (Telecommunication, Computing, Electronics and Control), Vol.11, No.3, September 2013.

[5] Ali M. Fadhil, Haider M. AlSabbagh, " The function of dream sleep ", TELKOMNIKA (Telecommunication, Computing, Electronics and Control), Vol.10, No.1, March 2012.

[6] Kashif Naseer Qureshi, Abdul Hanan Abdullah, Raja Waseem Anwar, " Wireless Sensor Based Hybrid Architecture for Vehicular Ad hoc Networks" TELKOMNIKA (Telecommunication, Computing, Electronics and Control), Vol.12, No.4, December 2014.

[7] Ali Hassan Sodhro, Ye Li, Madad Ali Shah, " Novel Key Storage and Management Solution for the Security of Wireless Sensor Networks", TELKOMNIKA (Telecommunication, Computing, Electronics and Control), Vol. 11, No. 6, June 2013.

[8] Mahyastuty, V. Windha; Pramudita, A. Adya, "A video-based alarm clock for smart bedrooms ", TELKOMNIKA (Telecommunication, Computing, Electronics and Control), Vol. 12 Issue 4, 2014.

[9] Muhammad Anwar, Abdul Hanan Abdullah, Kashif Naseer Qureshi, Abdul Hakeem Majid, Perimeter Security Sensor Technology: An Overview, TELKOMNIKA (Telecommunication, Computing, Electronics and Control), Vol.15, No.3, September 2017.

[10] Javed Iqbal Bangash, Abdul Hanan Abdullah, Abdul Waheed Khan, Mohammad Abdur Razzaque, Rohana Yusof, "Critical Data Routing (CDR) for Intra Wireless Body Sensor Networks", TELKOMNIKA (Telecommunication, Computing, Electronics and Control), Vol.13, No.1, March 2015.

[11] Khalid Haseeb, Kamalrulnizam Abu Bakar, Abdul Hanan Abdullah, Adnan Ahmed, " The alarm, sensor and security circuit ", TELKOMNIKA (Telecommunication, Computing, Electronics and Control), Vol.13, No.1, March 2015.

[12] Rania Khadim, Mohammed Erritali, Abdelhakim Maaden, " smart alarm Schemes for Wireless Sensor Networks", TELKOMNIKA Indonesian Journal of Electrical Engineering, Vol. 16, No. 2, November 2015.

[13] Xiaofan Wu, Chun Chen, Jiajun Bu, " An Interference-aware Transmission alarm Scheme for Vehicular On-board Monitoring Wireless Sensor Network", TELKOMNIKA (Telecommunication, Computing, Electronics and Control), Vol.10, No.5, September 2012.

[14] Zhibin Hao, Wenbin Li, Jiangming Kan, Liyuan Jiang, Chao Feng, " Performance Evaluation of Wireless Sensor NetworksBased OnZigbee Technology in Smart Home" Energy for Wireless Sensor Networks", TELKOMNIKA (Telecommunication, Computing, Electronics and Control), Vol. 11, No. 8, August 2013.

[15] Nima Bahrami, Nor Hisham Haji Khamis, Ameruddin Baharom, Azli Yahya, " smart alarm Characterization to Design Wireless Sensor Network by Bellhop", TELKOMNIKA (Telecommunication, Computing, Electronics and Control), Vol.14, No.1, March 2016.

[16] Mohsen Nasri, Abdelhamid Helali, Halim Sghaier, Hassen Maaref," Efficient Scheme for Multihop alarm in Wireless Networks", TELKOMNIKA (Telecommunication, Computing, Electronics and Control), Vol.9, No.2, August 2011.

[17] Rony Teguh, Hajime Igarashi, "Optimization of Sensor Network Topology ZIGBEE BASED HOME AUTOMATION WIRELESS SENSOR NETWORK ", TELKOMNIKA (Telecommunication, Computing, Electronics and Control), Vol.13, No.2, June 2015.

[18] Enjian Bai, Xueqin Jiang, A Dynamic Key Management Scheme Based on Secret Sharing for Hierarchical Wireless Sensor Networks, TELKOMNIKA (Telecommunication, Computing, Electronics and Control), Vol.3, No.11, 2013.

[19] Wang Huan, Xu Xiaoli, " Wireless Sensor Network in the Photovoltaic Power Generation Monitoring System" TELKOMNIKA (Telecommunication, Computing, Electronics and Control), Vol. 11, No. 8, August 2013.

[20] MY Hariyawan, et al., "Wireless Sensor Network for alarm dangerous Fire Detection," TELKOMNIKA, vol.11, no 3, 2013.

[21] Osamah Ibrahem Khalaf, Norrozila Sulaiman, Ghaidaa Muttasher Abdulsahib,2014.Analyzing Video Streaming Quality by Using Various Error Correction Methods on Mobile Ad hoc Networks in NS2", International Journal of Engineering Research and Applications. 4(10):pp.172-178.

[22] Yi Xinhua, Wang Mingjun, Cheng Xiaomin, " An Intelligent Self-Adjusting Sensor for Smart HomeServices based on ZigBee Communications ", T TELKOMNIKA (Telecommunication, Computing, Electronics and Control), Vol.10, No.8, December 2012.

[23] J.A. Koenig and Mr. L. Taylor, "Perimeter Security Sensor Technology hand book", ElectronicSecurity Systems Engineering Division, North Charleston, U.S.A, Page 67-86.

[24] Thomas Petruzzelis, "The alarm, sensor and security circuit book", TAB Books. Imprint of McGrawhill.

[25] Zungeru, A..M., Edu, U., \& Garba, A. (2012). Design and Implementation of a Short Message Service Based Remote Controller. Computer Engineering and Intelligent systems, 3(4), 106-119.

[26] Osamah Ibrahim Khalaf, Ghaida Muttashar Abdulsahib and Muayed Sadik, 2018. A Modified Algorithm for Improving Lifetime WSN. Journal of Engineering and Applied Sciences, 13: 9277-9282. 
[27] S.Taruna, Kusum Jain, G.N. Purohit, Department of Computer Science, Banasthali University, Jaipur, Rajasthan, India "Application Domain of Wireless Sensor Network: - A Paradigm in Developed and Developing Countries" IJCSI International Journal of Computer Science Issues, Vol. 8, Issue 4, No 2, July 2011.

[28] Yazeed Al-Obaisat, Robin Braun Institute of Information and Communication Technologies University of Technology, Sydney, Australia “On Wireless Sensor Networks: Architectures, Protocols, Applications, and Management"

[29] Ghaida Muttashar Abdulsahib and Osamah Ibrahim Khalaf, 2018. An Improved Algorithm to Fire Detection in Forest by Using Wireless Sensor Networks. International Journal of Civil Engineering \& Technology (Ijciet) - Scopus Indexed.Volume:9,Issue:11,Pages:369-377.

[30] N. Sulaiman, G. Abdulsahib, O. Khalaf, M. N. Mohammed, "Effect of Using Different Propagations of OLSR and DSDV Routing Protocols", Proceedings of the IEEE International Conference on Intelligent Systems Structureing and Simulation, pp. 540-545, 2014

\section{BIOGRAPHIES OF AUTHORS}

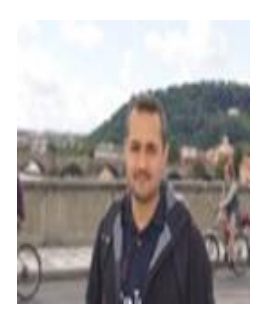

Ayman Dawood Salman has finished his B.Sc. degree in Electrical and Electronic Eng. From University of Technology-Baghdad in 1998 and got his M.Sc. in Computer and Information Technology/Software Engineering from the University Technology-Baghdad also in 2004. Then he Graduated in Doctor Eng. degree in the Communication Networks Group, Institute of Information Technology, Technical University of Ilmenau, Germany. Primary research focuses on MANETs with an emphasis on QoS routing and multimedia communication, IoT, WSN, and SDN. Currently his works as a lecturer at university of technology - Department of computer engineering.

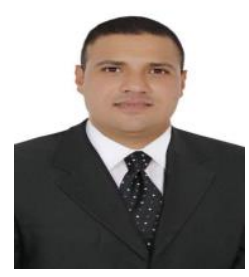

Osamah Ibrahim Khalaf is Senior Engineering and Telecommunications Lecturer in Al-Nahrain University/College of Information Engineering. He has hold 10 years of university-level teaching experience in computer science and network technology and has a strong CV about research activities in computer science and information technology projects. He has had many published articles indexed in (ISI/Thomson Reuters) and has also participated and presented at numerous international conferences. He has a patent and has received several medals and awards due to his innovative work and research activities. He has good skills in software engineering including experience with: .Net, SQL development, database management, mobile applications design, mobile techniques, Java development, android development, IOS mobile development, Cloud system and computations, website design. His brilliant personal Strengths are in hghly selfmotivated team player who can work independently with minimum supervision, strong leadership skills, and outgoing personality. In 2004, he got his B.Sc. in software engineering field from Al_Rafidain University College in Iraq. Then in 2007, he got his M. Sc. in computer engineering field from Belarussian National Technical University. After that, he got his PhD in 2017 in the field of computer networks from faculty of computer systems \& software engineering -University Malaysia, Pahang. He has overseas Work experiences in University in Binary Unive

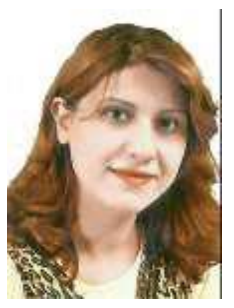

Ghaida Muttshar Abdulsahib got her B.Sc. in 2007. in computer engineering field from University of Technology Iraq. Then in 2012, she got her M. Sc.in Computer Networking and after that she got her PhD in 2017 in the field of computer network from Faculty of computer systems \& software Engineering-University Malaysia Pahang. She has patents and has also received several medals and awards for her innovative researches in computer science, computer engineering and information technology. Now she is a Senior Engineering and Telecommunications Lecturer in University of Technology and she has 10 years of university-level teaching experience in computer science and network technology. She has a strong CV due to her implemented projects in computer science and networking. She has had many published articles in ISI/Thomson Reuters indexed journals and she has also presented at many international conferences. She has good skills in software engineering including experience with: .Net, SQL development, database management, mobile applications design, mobile techniques, Java development, android development, IOS mobile development, Cloud system, website design and so on. Her personal Strengths and abilities are in highly self-motivated team player who can work independently with minimum supervision, strong leadership skills, and outgoing personality. She has overseas Work experiences in International University of Malaya-Wales in Malaysia and University Malaysia, Pahang. 